\title{
A IMPORTÂNCIA DA AULA PRÁTICA DE CIÊNCIAS PARA O ENSINO FUNDAMENTAL II
}

\author{
Carolina de Arsolino Almeida ${ }^{1}$ \\ Ludmila Amitrano Mannarino ${ }^{2}$
}

RESUMO: O processo educativo acontece através da interação do discente com o meio em que ele está inserido, através de desafios que agucem a curiosidade do aluno, assim promovendo a aprendizagem. $\mathrm{O}$ ensino de ciências abrange diversos conceitos de difícil compreensão, fazendo com o que esta metodologia de aula seja facilitadora. De acordo com a proposta do Parâmetro Curricular Nacional (PCN - BRASIL, 200o) a prática dos experimentos na aula de Ciências serve como metodologia entre o aprendizado teórico $\mathrm{x}$ prático a fim de dar continuidade na formação deste aluno. Muitos alunos esquecem o verdadeiro sentido e objetivo das aulas práticas e dos experimentos, comportando-se como se estivessem em um "parque de diversões". De acordo com Ronqui et.al (2009), a aula prática tem como função primordial, estimular a curiosidade científica dos alunos. Este ensino pode e deve ser trazido também para o ambiente da sala de aula, pois proporciona diversas situações nas quais os alunos irão poder se portar como verdadeiros cientistas.

Palavras-chave: Aula prática. Docente. Sala de aula. Experimentos.

\section{INTRODUÇÃO}

A análise de reflexões de professores nas salas de aula durante o período de Estágio Supervisionado nos faz pensar nos desafios de buscar subsídios de uma prática eficiente e voltada a mudanças de posturas críticas no ensino da ciência para os alunos. A intenção não é questionar a formação do docente, mas sim, a transmissão dos conteúdos em teoria prática. Sendo importante que o docente acreditasse que tal conhecimento teria mais eficiência no momento em que o aluno pudesse obter a transformação do conteúdo.

De acordo com Andrade e Massabni (20II), as atividades práticas levam a adquirir os conhecimentos prévios, e que em uma aula dialogada e ou demonstrativa, não proporcionaria o conhecimento, já que é um compromisso do professor, juntamente com a

\footnotetext{
I Graduada em biologia pela Universidade Salgado de Oliveira - São Gonçalo - Rio de Janeiro. Pósgraduação em ensino da biologia pela faculdade Faveni. E-mail: carolarsolino@live.com.

${ }^{2}$ Professora orientadora.
} 
Unidade Escolar, oferecer esta oportunidade de ensino a todos, independente de ser escola pública ou privada.

A atividade prática faz com o que o professor esteja envolvido diretamente com o aluno, Porém esta aula pratica deve ser trazida para dentro da sala de aula, lembrando que fazer ciências não faz com que o que os alunos memorizem algo pronto, como sendo verdade absoluta, mas acabam reelaborando e problematizando concepções e se convencendo de determinadas ideias e explicações possíveis, as quais são acessadas pela argumentação.

Fazer o uso de experiencias como o início para desenvolver a compreensão de conceitos, é uma forma do professor fazer e levar o aluno a buscar participação no seu processo ensino aprendizagem, saindo da posição de observador e que comecem a agir como um ser ativo da prática, explicitando suas idéias e curiosidades. (CARVALHO et al, 1999, p.47)

O uso dos experimentos deverá possibilitar que os discentes percebam erros e analisem as informações transmitidas e obtidas, comparando-as com seu conhecimento adquirido durante as aulas. Os erros jamais devem ser deixados de lado, deixados para depois, mas sim valorizados para gerar debates, discussões, reflexões e até fazer o uso da capacidade de raciocínio.

A experimentação no ensino de ciências seja está na sala de aula ou no laboratório é importante, pois contribui com o desenvolvimento global do indivíduo, auxiliando-o na aquisição de novos conhecimentos. Quando o professor permite aos seus alunos pensarem ao invés de pensar por eles, este está favorecendo a autonomia intelectual dos mesmos e preparando-os para atuar em forma competente, criativa e crítica, conforme sugere (Garrido, 2002).

Esta abordagem metodológica enfatiza a iniciativa do aluno porque cria oportunidade para que ele defenda suas idéias com segurança e aprenda a respeitar as idéias dos colegas. Dá-lhes também a chance de desenvolver variados tipos de ações - manipulações, observações, reflexões, discussões e escrita. (CARVALHO et al, 1998, p.20)

Infelizmente, na maioria das vezes as aulas práticas são realizadas nos moldes do ensino tradicional, propondo-se apenas a fazer com que os alunos sigam a roteiros (moldes), com resultados já conhecidos ou como a ilustração da teoria (ANDRADE e MASSABNI, 20II), sem que haja o conceito de aprendizagem transformadora. 
É de suma importância entender e conhecer a concepção das aulas práticas e experimentais como meio de transformação do indivíduo, com a finalidade de contribuir para uma sociedade justa, considerando que o estudo das ciências enfatiza a busca de uma nova visão de leitura de mundo e seus recursos (VASCONCELOS et.al., [s.d]).

Levando em consideração que, as aulas de ciências de forma prática promovem uma assimilação concreta dos conteúdos, possibilitando o discente a ter uma formação de uma consciência crítica do saber científico tornando-o capaz de criticar, buscar novos conhecimentos, questionar o meio, criar oportunidades e formular novos interesses na busca de esclarecimento de novas buscas.

\section{DESENVOLVIMENTO}

Diversos tipos de ensino atuais resumem-se na teoria do desenvolvimento cognitivo de Piaget. De acordo com ele, a mente humana tende a operar em equilíbrio e a elevar constantemente seu grau de organização interna e de adaptabilidade ao meio. Quando sujeita a novas informações esse equilíbrio é rompido e a mente reestrutura-se, desenvolvendo novos métodos de integração e visando buscar atingir outra vez o equilíbrio, possibilitando desse modo, o desenvolvimento cognitivo (MOREIRA, 1999).

Sobre a experimentação no ensino de ciências, NANNI argumenta:

O que se vê ainda na maioria das escolas são aulas de física, química e biologia meramente expositiva, presa às memorizações, sem laboratório $e$ sem relação com a vida prática cotidiana do aluno. Essa maneira simplista, ultrapassada e, até mesma, autoritária de conceber o processo de ensino, certamente não deixa transparecer a complexidade que caracteriza todo o ato de ensinar. (NANNI, 2004, p.I).

É importante ressaltar que propor uma mudança pedagógica do professor em sala de aula onde existe uma proposta curricular de ciências, é preciso que o professor problematize os conteúdos e conceitos aplicados, consciente na busca de um conhecimento onde se desperte, estimule a curiosidade dos alunos na aquisição de um conhecimento científico .

O professor de ciências deve levar em consideração o momento pessoal do desenvolvimento do aluno, nesta etapa tornando-o interessante e significativo à experimentação metodológica em sua aula. De uma forma equivocada, as atividades de ciências, aplicadas nas aulas, não levavam em muitas vezes e ainda não leva em 
consideração pelos professores tradicionais a importância da experimentação como momento de busca de novos conhecimentos. (GASPAR, 2009).

[...] o experimento, por si só não garante a aprendizagem, pois não é suficiente para modificar a forma de pensar dos alunos, o que exige acompanhamento constante do professor, que devem pesquisar quais são as explicações representadas pelos alunos para os resultados encontrados e necessário, uma nova situação de desafio. (BIZZO, 2002, p.75)

Gaspar (2009) também ressalta que é importante lembrar que só o experimento não será suficiente para o desenrolar da aquisição do conhecimento científico pelo aluno, e sim, deverá haver uma relação de união entre teoria - prática.

A experimentação torna possível ao estudante refletir sobre o mundo de forma empírica expandindo seu conhecimento sobre a natureza e promovendo competências como a observação, a obtenção e a organização de dados, bem como a reflexão e a debate. Logo, é possível desenvolver conhecimento a partir de ações e não apenas através de aulas expositivas, tornando o aluno o indivíduo da aprendizagem (VIVIANI; COSTA, 20Io).

Os Parâmetros Curriculares Nacionais de Ciências Naturais (PCN's) são direcionados aos educadores com o objetivo de aprofundar na prática pedagógica do ensino de ciências em todas as escolas de ensino fundamental II, para que haja uma contribuição no planejamento do seu trabalho e para um possível projeto pedagógico anual.

Quando se é dito em ensino de ciências por investigação, sugerimos imagens diversas de aulas sobre ciências, no qual o docente faz anotações no quadro, seguindo das explicações e os discentes anotando e sendo ouvintes enquanto o professor disserta sobre algum determinado tema do conteúdo, fazendo com o que este ensino aproxime cada vez mais a ciência dos cientistas e com a ciência escolar.

Sobre o ensino de ciências por investigação:

Uma atividade de investigação deve partir de uma situação problematizadora e deve levar o aluno a refletir, discutir, explicar, relatar, enfim, que ele comece a produzir seu próprio conhecimento por meio da interação entre o pensar, sentir e fazer. Nessa perspectiva, a aprendizagem de procedimentos e atitudes da aprendizagem, tão importante quanto à aprendizagem de conceitos e/ou conteúdos. (AZEVEDO, 2014) 
Devemos elaborar atividades investigativas para uma melhor construção de conceitos, aproveitando para se utilizar de forma a oferecer oportunidade ao discente de contribuir para o seu processo ensino aprendizagem.

Conforme Bachelard (1938, p.73), "todo conhecimento é a resposta de uma questão", o que nos leva a pensar como é a importância dos experimentos desde as séries iniciais da Educação Básica.

Essa proposta de ensino deve ser tal que leve os discentes a construir seu conteúdo conceitual participando do processo de construção e dando oportunidade de aprenderem a argumentar e exercitar a razão, em vez de fornecer-lhes respostas definitivas ou impor-lhes seus próprios pontos de vista transmitindo uma visão fechada das ciências. (CARVALHO, 2004, p.)

A experimentação investigativa na qual o discente é encaminhado à resolução de problema, que é uma 'experiência enriquecedora que se testa inúmeras vezes com ideias e hipóteses diferentes sobre quo o discente (investigador) tinha de concreto". (Astolfi et.al, I998, p 109 - grifo dos autores). De acordo com Moreira (1983), a resolução de problemas que leva a uma investigação deve estar fundamentada na ação dos alunos. Os discentes devem ter a oportunidade de agir e o ensino deve ser observado e analisado através de ações e demonstrações que o levem a um bom e construtivo trabalho prático.

A didática sem uma prática de ensino equivalente perde todo o seu significado, ganhando somente validade se for seguido por ações dos docentes em suas devidas turmas, de uma forma que esta prática produza um conhecimento e aprendizagem significativa em seus alunos. (Carvalho et al. 1999, p. 47).

Para a elaboração do planejamento de uma aula prática-experimental produtiva faz-se necessário que o docente possa aprimorar o lógico e desenvolva o seu raciocínio indutivo e dedutivo, que é o que leva a problematização do assunto, sendo de responsabilidade do professor. Esse só deve fazê-la se já tiver um bom acúmulo de conhecimentos e leituras a respeito. Este conhecimento é primordial para o bom desenvolvimento das atividades de experimentos e servindo para guiar os alunos em suas análises, após isso o professor deverá redigir um roteiro de aula prática, pois ele é o agente do processo, orientando as observações e dando as explicações cabíveis aos assuntos relacionados à aula ou até mesmo a interdisciplinaridade do conteúdo trabalhado sendo interligado com outras disciplinas como: química e/ou física, surgindo assim introduções a 
conteúdos a serem trabalhos nestas outras disciplinas ou então dúvidas explicadas, pela presença desta metodologia.

Nas experiências científicas os alunos estarão mais aptos a formar o conhecimento, pois eles ficarão em contato direto com os fenômenos, tendo assim, uma variabilidade única (individual) e é por isso que se faz se faça necessário o trabalho em grupos, pois desta forma, os resultados podem não estar previstos, pois a interpretação irá desafiar a sua imaginação e raciocínio (GASPAR, 2005)

O professor deve reconhecer sua incompletude e a dos alunos, atingindo sobre estas, a busca pelo aprimoramento "Estar sendo é a condição, entre nós, para ser" (Freire, 2006, p. 33). Um processo educativo problematizador, portanto, deve deflagrar no aprendiz um interesse, cada vez maior, e quanto mais crítico é o ato de aprendizado mais a curiosidade torna-se epistemológica (Freire, 2006). Isso define a transição da ingenuidade à criticidade, da curiosidade ingênua à curiosidade epistemológica.

O experimento deve ser apresentado previamente a qualquer discussão teórica. Os estudantes fazem seus registros transcritos de forma ordenada, organizada e profunda. Com essa intenção pode-se realizar uma ficha de análise experimental. Tal ficha deve possuir os materiais a serem usados nos procedimentos experimentais, instruções para observações e notas, além de perguntas e indagações que façam com que os alunos reflitam sobre suas anotações e sobre os resultados experimentais de forma a elaborar quaisquer explicações para seus achados. Nessa atividade, os educandos realizam o que Freire (2005) denomina de leitura-de-mundo. Os educandos quando observam e procuram esclarecer fenômenos naturais, estão fazendo uma leitura deste que pode ser entendida como leiturade-mundo.

De acordo com Tamir (1991), um dos principais problemas com o laboratório de ciências é que se busca alcançar uma pluralidade de objetivos, nem sempre compatíveis, com um mesmo tipo de atividade. É certo que, com um mesmo conjunto de materiais, um professor criativo pode planejar diversas atividades diferentes, com objetivos nitidamente diversos como, por exemplo, aprender a utilizar um instrumento para realizar leituras, conseguir uma imagem de um fenômeno ainda não percebido, aprender estratégias para lidar com os erros e incertezas inerentes quando processo de medição, procurar relatos de atividade da presença de qualquer relação entre grandezas envolvidas na situação e outros. 
A questão que se coloca é: o laboratório pode ter um papel mais relevante para a aprendizagem escolar? Se pode, de que maneira ele deve ser organizado? A resposta para a primeira questão é sem dúvida afirmativa: o laboratório pode, e deve ter um papel mais relevante para a aprendizagem de ciências. O fato de estarmos insatisfeitos com a qualidade da aprendizagem, não só de ciências, sugere que todo o sistema escolar deve ser continuamente repensado. Com raras exceções, não se cogita a extinção da escola, por causa de suas dificuldades. Da mesma forma, o que precisamos é encontrar novas maneiras de usar as atividades prático-experimentais mais criativa e eficientemente e com propósitos bem definidos, mesmo sabendo que isso apenas não é solução para os problemas relacionados com a aprendizagem de ciências.

Para que as aulas de laboratório se tornem mais interessantes, é importante uma ambientalização do laboratório com plantas, peixes e invertebrados, para que os alunos tenham contato direto com os seres vivos. Além disso, outro aspecto importante de uma aula em um laboratório é que não pode ser silencioso como uma biblioteca, uma vez que vários grupos de alunos estarão trabalhando ao mesmo tempo, cada um em seu ritmo. Mas deve-se evitar o excesso de barulho e limitar o trânsito de pessoas ao mínimo necessário. Mesmo que exista um técnico de laboratório encarregado de preparar e guardar o material das aulas, é importante que o próprio grupo de alunos, ao terminar suas atividades, deixe tudo como foi encontrado. (Capeletto, 1992).

Para a realização de práticas de laboratório, não são necessários aparelhos e equipamentos caros e sofisticados. $\mathrm{Na}$ falta deles, é possível, de acordo com a realidade de cada escola, o professor realizar adaptações nas suas aulas práticas a partir de materiais existentes e, ainda, utilize materiais de baixo custo e de fácil acesso. (Capeletto, 1992).

$\mathrm{Na}$ vida cotidiana as experiências são realizadas constantemente. Para o filósofo (DEWEY, 1980) a experiência e a aprendizagem não podem ser separadas.

Uns exemplos de como as experiências atuam na aprendizagem, promovendo modificações significativas na compreensão do aprendiz é:

Uma árvore pode ser somente um objeto da experiência visual, pode passar a ser percebida de outro modo se entre ela e a pessoa se processarem outras experiências como a utilidade, aspectos medicinais, econômicos, etc.. Isso fará o indivíduo perceber a árvore de modo diferente. Depois dessa experiência, o indivíduo e a árvore são diferentes do que eram antes. (DEWEY, 1980, p.II4) 
A experiência se adquire a partir de um conjunto de vivências. Nesse sentido, quando a experiência educativa é refletida, a aquisição de conhecimento será seu resultado natural, portanto, a experiência dá significado à vida (ROSITO, 2008).

É importante considerar que os fenômenos práticos do Ensino de Ciências não devem estar limitados àqueles que podem ser criados e reproduzidos na sala de aula ou no laboratório, mas sim permitir que se permeiem pelas negociações de significado do ponto de vista dos alunos. As vivências e ocorrências do mundo social, ao serem incluídas na aula, possibilitam que as formas como os conceitos funcionam nas relações sociais possam ser experienciadas pelos alunos (MACHADO, 1999).

Para que os aprendizes tenham acesso aos sistemas de conhecimento da ciência, o processo de construção do conhecimento tem que ultrapassar a investigação empírica pessoal. Quem aprende precisa ter acesso não apenas às experiências físicas, mas também aos conceitos e modelos da ciência convencional. O desafio está em ajudar os aprendizes a se apropriarem desses modelos, a reconhecerem seus domínios de aplicabilidade e, dentro desses domínios, a serem capazes de usá-los. Se ensinar é levar os estudantes às idéias convencionais da ciência, então, a intervenção do professor é essencial, tanto para fornecer evidências experimentais apropriadas como para disponibilizar para os alunos as ferramentas e convenções culturais da comunidade científica. (DRIVER et. al., 1999 p.34).

A escola, ao separar o contexto teórico do contexto prático, contribui para que o poder de estudo seja diminuído, juntamente com o desenvolvimento intelectual e a possibilidade de contribuição para a melhoria da qualidade de vida da população. É nesse sentido que Mortimer, Machado e Romanelli afirmam que:

[...] o pressuposto de que se deva, no ensino, esgotar um conceito para poder aplicá-lo pode ser questionado, pois é justamente nas aplicações do conceito que se explicitarão as relações a serem estabelecidas entre os conceitos. Além disso, existem tendências na psicologia contemporânea que consideram os conceitos inseparáveis dos contextos de aplicação, uma vez que o aluno tende a recuperar conceitos a partir desses contextos de aplicação e não no vazio (MORTIMER; MACHADO; ROMANELLI, 2000, 0.275$)$.

\section{CONCLUSÃO}

Conclui-se que transformar os conteúdos de ciências para uma forma onde possibilite uma busca de uma consciência científica (curiosa) não é fácil, porém, se faz 
necessário, para que o aluno seja instigado à curiosidade, buscando sempre novos conhecimentos. Sabendo que a aula em laboratório se promove em uma aprendizagem mais eficiente, pois estimula as habilidades cognitivas e motoras dos alunos. O objetivo do uso do laboratório de ciências é proporcionar uma melhoria na prática educativa dos discentes.

Portanto este artigo enfatiza que as aulas práticas não são somente soluções para os demasiados problemas enfrentados nos ensinos destas matérias, porém, é um importante instrumento a ser utilizado, e uma vez utilizado com critério, poderá levar ao aumento da motivação e consequentemente o influenciando para que haja uma boa solidificação do aprendizado.

Sugere-se levarmos a participação deste aluno para um processo de investigação de um determinado fenômeno e isso os levarão a criar hipóteses, análises, interpretações dos resultados criados pelos mesmos. Por isso, uma atividade deve ser considerada investigativa, nela é priorizada a participação do aluno como um ser pensante e ativo no processo de aquisição do conhecimento.

Ficando claro que as escolas ao investir na construção deste ambiente educacional, tornarão as aulas de ciências mais produtivas. Neste ambiente se fará necessário o manuseio de instrumentos e equipamentos, por isso a presença do professor se fará necessária. O docente deverá também, orientar todos sobre dúvidas das investigações realizadas pelos alunos.

Em virtude do que foi mencionado, a não realização de atividades experimentais no ensino de ciências e/ou biologia, foge de algo. Com base neste estudo pode-se afirmar que os profissionais são capazes de superar os obstáculos enfrentados para um ensino prático, podendo adotar medidas e estratégias para facilitar a aprendizagem, sendo ela em sala de aula, laboratório ou em campo. Além disso, este estudo me proporcionou a descoberta da amplitude desta metodologia de aula, como um grandioso instrumento educacional.

\section{REFERÊNCIAS}

ASTOLFI, Jean-Pierre; PETER FALVI, Brigitte; UERN, Anne. Como as crianças aprendem as ciências. Tradução: Maria José Figueiredo. Lisboa, Portugal; Instituto Piaget, 1998. Acesso em: 20/07/2018. 
AZEVEDO, M.C.P.S. Ensino por investigação: problematizando as atividades em sala de aula. In: CARVALHO, A.M.P. (Org). Ensino de ciências: unido à prática e a pesquisa. São Paulo: Pioneira Thomson Learning, 2004, p.19-33. Acesso em: II/o7/2018.

BARROS, Jussara de. "A aula de laboratório-lugar de aprendizagem"; Brasil Escola. Acesso em: 27/07/2018.

BORDENAVE, J.D; PEREIRA, A.M. Estratégias de ensino: aprendizagem. $7^{\underline{a}}$ ed. Petrópolis, Rio de Janeiro; Vozes Ltda., 1985. Acesso em: 10/o8/2018.

BRASIL. Parâmetros Curriculares Nacionais: Ciências Naturais/ Secretaria de Educação Fundamental. Brasília: MEC/SEF, 1998. Acesso em: 14/o7/2018.

CAPETEletTO, A. Biologia e Educação Ambiental: Roteiros de trabalhos. Editora ática, 1992 p.224. Acesso em 28/o7/2018.

CARVALHO, A.M.P (cord) Termodinâmica: Um ensino por investigação. São Paulo: Feursp, 1999. Acesso: 28/o7/2018.

CARVALHO, A.M.P. et al. Ciências no Ensino Fundamental: o conhecimento físico. São Paulo: Scipione, 2009. Acesso em: 25/07/2018.

CARVALHO, A.M.P. O ensino de ciências e a proposição de sequência de ensino 796 investigativo. In: CARVALHO, A.M.P (Org.) Ensino de ciências por investigação: Condição para implementação em sala de aula. São Paulo: Cengage Learning, p. I-20, 2013. Acesso: 03/07/2018.

CARVAlHO, Anna Maria Pessoa de. Anna Maria Pessoa de Carvalho (Org). O ensino de ciências: unindo a pesquisa e a prática. São Paulo, 2004, p.r. Acesso em: 03/o7/2018.

CHAlmerES, A.F. Afinal o que é Ciência afinal? São Paulo: Brasilense, 1999. Acesso em: $03 / 07 / 2018$.

DE CARVALHO, A.M.P. (Org.); Ensino de ciências unindo a pesquisa e a prática. São Paulo; Pioneira THOMSON LEARNING, 2004. Acesso em: 07/o7/2018.

DEWEY, J. Experiência e natureza: lógica a teoria da investigação: A com experiência: vida e educação. Teoria da vida moral. São Paulo: Abril Cultural, 198o. Acesso em: 29/07/2018.

DOURADO, L. Trabalho Prático, trabalho laboratorial, trabalho de campo e trabalho experimental no Ensino de ciências - contributo para clarificação do termo. In: VERÍSSIMO, A., PEDROSA, A.A.; RIBEIRO, R. (Orgs). (Re)pensar o ensino de 
ciências. Departamento do ensino secundário. Portugal: Ministério do Ensino Secundário. Portugal: Ministério da Educação, 200I. Acesso em: 26/o72018.

DRWER, R.; ASOKO, H.; LEACH, J.; MORTIMER, E.F.; MACHADO, A.H.; ROMAANELLI, I.A. Proposta Curricular de Química do Estado de Minas Gerais: Fundamentos e Pressupostos. Química Nova Escola. São Paulo, v.I, noำ, p.31-40, Maio de 1999. Acesso em: 29/o7/2018.

HODSON, D. Experimentos in Science teaching: Educational Philosophy and Theay. V.20, no 2, 1988. Acesso em: 07/o7/2018.

Https://www.escolaweb.com.br/blog/aula-pratica-desenvolvendo-as-habilidades-dosalunos/ - Acesso em: 21/07/2018.

Https://www.brasilescola.uol.com.br/educacao/aula-labiratorio-lugar-aprendizagem/ Acesso em: 27/o7/2018

Https://www.blog.homolab.com.br/importancia-do-laboratório-de-ciencias-de-ensino/ Acesso em: 21/o7/2018.

Https://www.periodicos.ufpr.edu.br/actio/ - Acesso em: 25/o7/2018.

LEITE, L. Contributos para uma utilização mais fundamentada do trabalho laboratorial no ensino de ciências. In: CAETANO, H.V; SANTOS, M.G. (Org.). Cadernos Didáticos de Ciências r. Lisboa: Departamento do Ensino Secundário, 2001. Acesso em: 04/o7/2018.

LOPES, J.B. A revolução de problemas em Física e Química: modelo para estratégias de ensino-aprendizagem. Portugal, Texto editora, 1994. Acesso em: 26/o7/2018.

LÜDKE, M; ANDRÉ, M.E.D.A. Pesquisa em educação: abordagens qualitativas. São Paulo: Epu, 2001. Acesso em: 08/o7/2018.

LUNETA, V.N. Actividade práticas no ensino de ciências. Revista português de educação, v.2, n⿳⺈, p.8I-90, 1991. Acesso em: 27/o7/2018.

MACHADO, A.H. Aula de Química: discurso e conhecimento. Ijurí, UNIJUÍ, 199, p.20o. Acesso em: 28/o7/2018.

MALDANER, O.A. A formação inicial e continuada de professores de Química: Professor/Pesquisador. 2 ${ }^{\mathrm{a}}$ ed., Ijuí, editora Unijuí, 2003. Acesso em: 27/07/2018. MALHEIRO, J.M.da.S. Atividades experimentais no ensino de ciências. ACTIO. Curitiba, v.I, n-I, p.I08-I27, Jul-Dez 2016. Acesso em: 25/o7/2018. 
MAMPRIN, L.L. Implementação ou não de atividades experimentais em biologia no ensino médio: as revelações com saber profissional baseadas numa leitura Charlot (Mestrado em Ensino de Ciências e Educação em Matemática) Universidade de Londrina, Londrina-PR, 2007. Acesso em: 15/08/2018.

MOREIRA, M.A (1999). A aprendizagem significativa. Brasília. Editoria UnB. Revisado em 2012. Acesso em 21/o7/2018.

MORTIMER, E.F.; MACHADO, A.H.; ROMA NELLI, L.I.A. Proposta Curricular de Química do Estado de Minas Gerais: Fundamentos e Pressupostos. Química nova. São Paulo, v.23, n⿳⺈-2, p.273-383, Mar-Abr 200o. Acesso em: 28/o7/2018.

NANNI, R.A. Natureza do conhecimento científico e a experimentação no ensino de ciências. Revista Eletrônica de Ciências. São Carlo, noㅡㄹ, Maio de 2004. Acesso em: 28/o7/2018.

NIGRO, R.E. Ciências: soluções para dez desafios dos professores. São Paulo, editora ática, 2012. Acesso em: oI/o7/2018.

REVISTA de Educação em Ciências e Matemática \v.13(25), Jul-Dez, p.II6-134. Acesso em: I2/08/2018.

RONQUI, L.; SOUZA, M.R. de; FREITAS, F.J.C.de. A importância das atividades práticas na área da biologia. Revista Científica Facimed, vi, pi-9, 2009. Acesso em: 03/o8/2018.

ROSITO, B.A., O ensino de ciências e a experimentação. In: MORAES, R. (Org); Construtivismo e ensino de ciências: reflexões epistemológicas e metodológicas. Porto Alegre, ed. PUC RS, 2008. Acesso em: 20/07/2018.

SANTOS, W.L.P. Educação cientifica na perspectiva de letramento como prática social: Funções, princípios e desafios. Revista Brasileira de Educação, $\mathrm{n}^{\mathrm{o}}{ }_{12}$, v.36, p.474-492, SetDez de 2017. Acessado em: 20/07/2018.

SANTOS, C.S. Ensino de ciências: abordagem histórico-crítica. Campinas, São Paulo, Autores Associados, 2005. Acesso em: ol/o8/2018.

SOUZA, Alessandra Cardosina. A experimentação no ensino de ciências: Importâncias das aulas práticas no processo ensino-aprendizagem. 2013, folha 33, Monografia (especialização em educação: Metodologias e Técnicas de ensino). Universidade Tecnológica Federal do Paraná 
TAMIR, P. Pratical work at school: Ananalysis of current pratice. In: WOOL-NOUGH, B. (ed) Pratical Science. Milton Keynes: O pen University Press, 1991. Acesso em: 28/07/2018.

TOMITA, L.M.S. Trabalho de campo como instrumento de ensino de geografia. Londrina, v8, noำ, p.13-15, Jan-Jun, 1999. Acesso em: 09/o7/2018.

VASCONCElOS, A.L.S; COSTA, C.H,C; SANTANA, J.R.; CECCATO, V.M. Importância da abordagem prática no ensino de biologia para a formação de professores. (Licenciatura plena em Ciências/habilitação em biologia/química - UECE) em Limoeiro do Norte - CE. [S] [Sn] [Sd]. Acesso em: 21/o7/2018.

VIVIANI, D; COSTA, A. Práticas de ensino de Ciências Biológicas. Centro Universitário Leonardo da Vinci - Indial, grupo UNISDDELVI, 2010. Acesso em: 21/07/2018. 